\title{
Short Communication Article: \\ Citizen science highlights litter associated with COVID-19 as a potential threat on the island of Mindanao, Philippines: a marine biodiversity hotspot
}

\author{
Neil Angelo S. Abreo (corresponding author) \\ $\mathrm{AI}$ and Robotics Laboratory - Environmental Studies \\ University of the Philippines, Mindanao \\ nsabreo@up.edu.ph
}

\author{
Vladimer B. Kobayashi \\ AI and Robotics Laboratory - Environmental Studies \\ University of the Philippines, Mindanao
}

Publication Information:

Received 22 August 2021, Accepted 25 October 2021, Available online 28 December 2021

DOI: $10.21463 /$ jmic.2021.10.2.09

\begin{abstract}
The on-going COVID-19 pandemic is expected to exacerbate the marine litter problem. The use of disposable personal protective equipment (e.g., facemasks) will result to increase in marine plastics pollution. Here we explored the potential of citizen science to determine the distribution of marine litter associated with COVID-19 in Mindanao, Philippines. Volunteers were invited through social media, contributing geotagged photographs of marine litter associated with COVID-19. Although the information is limited, results showed the possible pervasiveness of marine litter associated with COVID-19. Since the waters surrounding the Southern Philippines is known to host high marine biodiversity, the potential negative interaction of marine litter associated with COVID-19 and marine species is inevitable. The contribution of citizen science to address some of the limitations on marine litter research is highlighted and is recommended to be explored further.
\end{abstract}

\section{Keywords}

COVID-19, facemask, marine litter, plastics pollution, citizen science, Philippines 
The role of personal protective equipment (PPE) during the pandemic is essential in containing the spread of the COVID19 virus (de Sousa, 2020). As a result, production of disposable PPEs greatly increased to cope up with the extremely high demand (Lee et al., 2020). With large parts of the global population using PPEs, it is expected that these materials are prone to improper disposal and add to the amount of litter in the environment. The on-going pandemic, therefore, is a major setback on the global efforts in reducing plastic wastes. Undoubtedly, these types of wastes will become marine litter, adding burden to the marine environment.

Marine litter, especially plastics, is a major problem in the Philippines (Abreo, 2018). The country's inefficiencies when it comes to solid waste management puts the Philippines as the $3^{\text {rd }}$ largest contributor of plastics to the marine environment (Jambeck et al., 2015). As part of the Coral Triangle, the Philippines host one of the highest marine biodiversity in the world and a possible hotspot for marine litter impacts in Southeast Asia (Coram et al., 2021; Lasut et al., 2018). With vast coastlines, logistics and funding constraints, data on marine litter in the country is currently limited. Given that these types of litter are relatively new, data on marine litter associated with COVID-19 in the Philippines are scarce.

To provide baseline data on the presence of marine litter associated with COVID-19, we recruited volunteers through social media to contribute geotagged photos of COVID-19 related litter in coastal areas of Mindanao, Philippines from 22 March 2021 to 6 August 2021. Using their personal smartphones, volunteers were asked to download free geotagging apps to capture photos with GPS coordinates (Fig. 1). GPS coordinates from each contributed photo was then plotted on a map using QGIS 3.12, an open-source geographic information system application (https://qgis.org) to look at the presence of COVID-19 litter in a relatively large spatial scale.

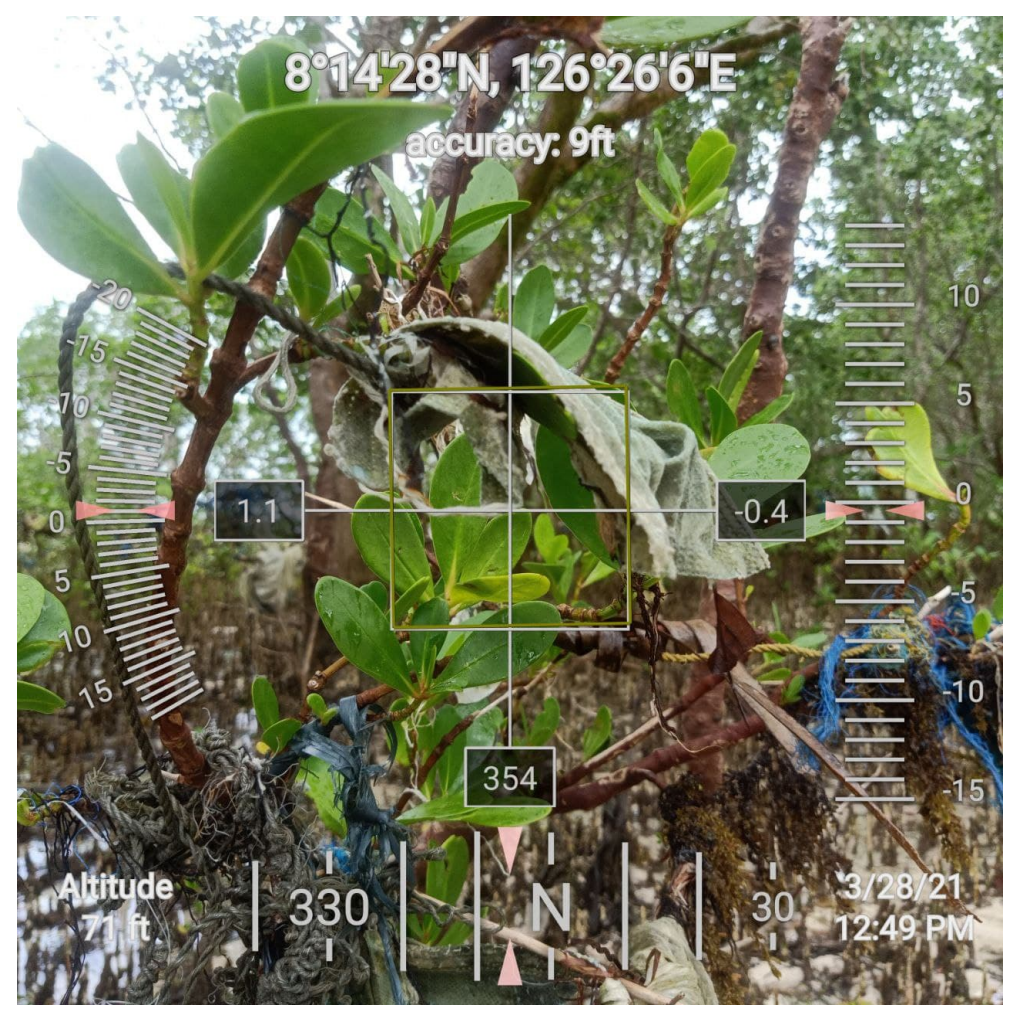

Fig 1. A photo contributed by a volunteer of a disposable facemask in a mangrove area in Northern part of Mindanao, Philippines, taken from a smartphone with geotagging app. Notice the coordinates on the top part of the photo that can be useful in distribution studies. (Photo by Michael Dann Superio) 
This simple method showed the widespread distribution of marine litter associated with COVID-19 in Mindanao, Southern Philippines (Fig. 2). Although data was limited to spatial distribution of litter, the method was kept simple to encourage more citizens to participate and ensure the quality of data is similar across all regions. Less complicated methodologies are a factor to consider when involving citizen scientists to ensure comparable data across large geographic scales (Burgess et al., 2017). Minimal technical knowledge is also required in identifying marine litter associated with COVID-19, making citizen science a viable method.

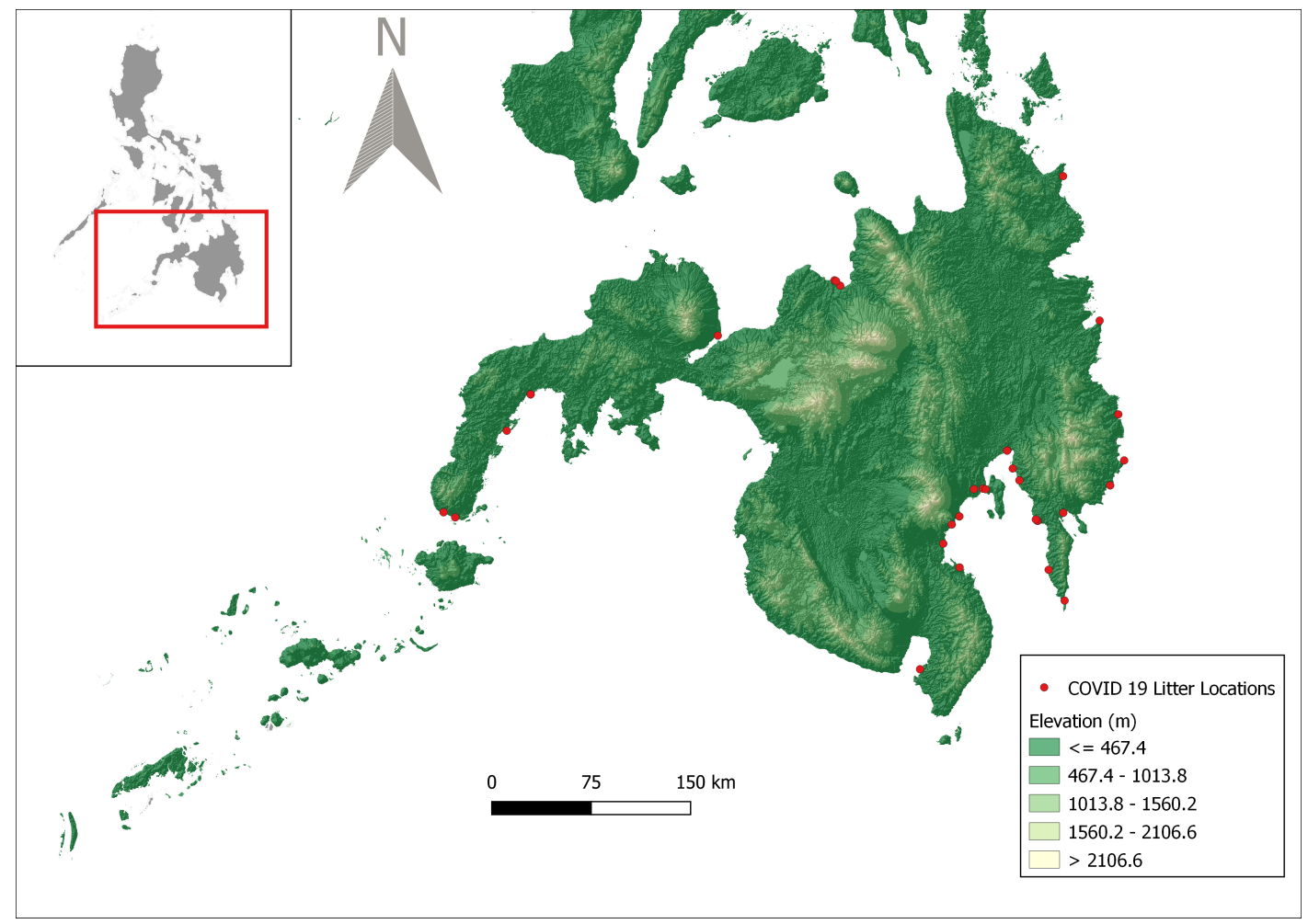

Fig 2. Distribution of marine litter associated with COVID-19 across Mindanao, Philippines.

Although certain limitations (Fig. 3) of the method applied here exist (e.g., motivation of people to participate, social media reach, and access to internet) (Hyder et al., 2015), the seemingly pervasive presence of litter associated with COVID-19 in the marine environment is an unwelcome development in the struggle to address the marine litter problem in the Philippines. With southern Philippine seas hosting very high marine biodiversity (Alcala et al., 2008), interaction between COVID-19 associated litter and marine fauna is inevitable, potentially leading to detrimental impacts (Hiemstra et al., 2021). It is important to note, that in pre-COVID-19 pandemic, the country already reported at least 18 marine species interacting with marine litter, often resulting to mortality of individual organisms (Abreo et al., 2019a, 2019b). With the addition of litter associated with COVID-19 in the marine environment, interaction of litter and wildlife is expected to increase. An initial study confirmed the presence of litter associated with COVID-19 on a beach in Mindanao, Philippines, with disposable face masks making up $2 \%$ of all identified litter (Abreo and Kobayashi 2021). This is worrisome as PPEs are expected to have the same impacts as the other types of marine macro-litter (e.g., ingestion and entanglement) (De-la-Torre and Aragaw, 2021). For example, in September 2020, a juvenile Magellanic penguin (Spheniscus magellanicus) died because of face mask ingestion in Sao Sebastiao, Brazil (Neto et al., 2021). Meanwhile, a freshwater perch (Perca fluviatilis) was also recorded entrapped in a PPE glove in the Netherlands (Hiemstra et al., 2021). 
Moreover, disposable face masks are a potential source of secondary microplastics as it breaks up into smaller pieces in the marine environment (Fadare and Okoffo, 2020).

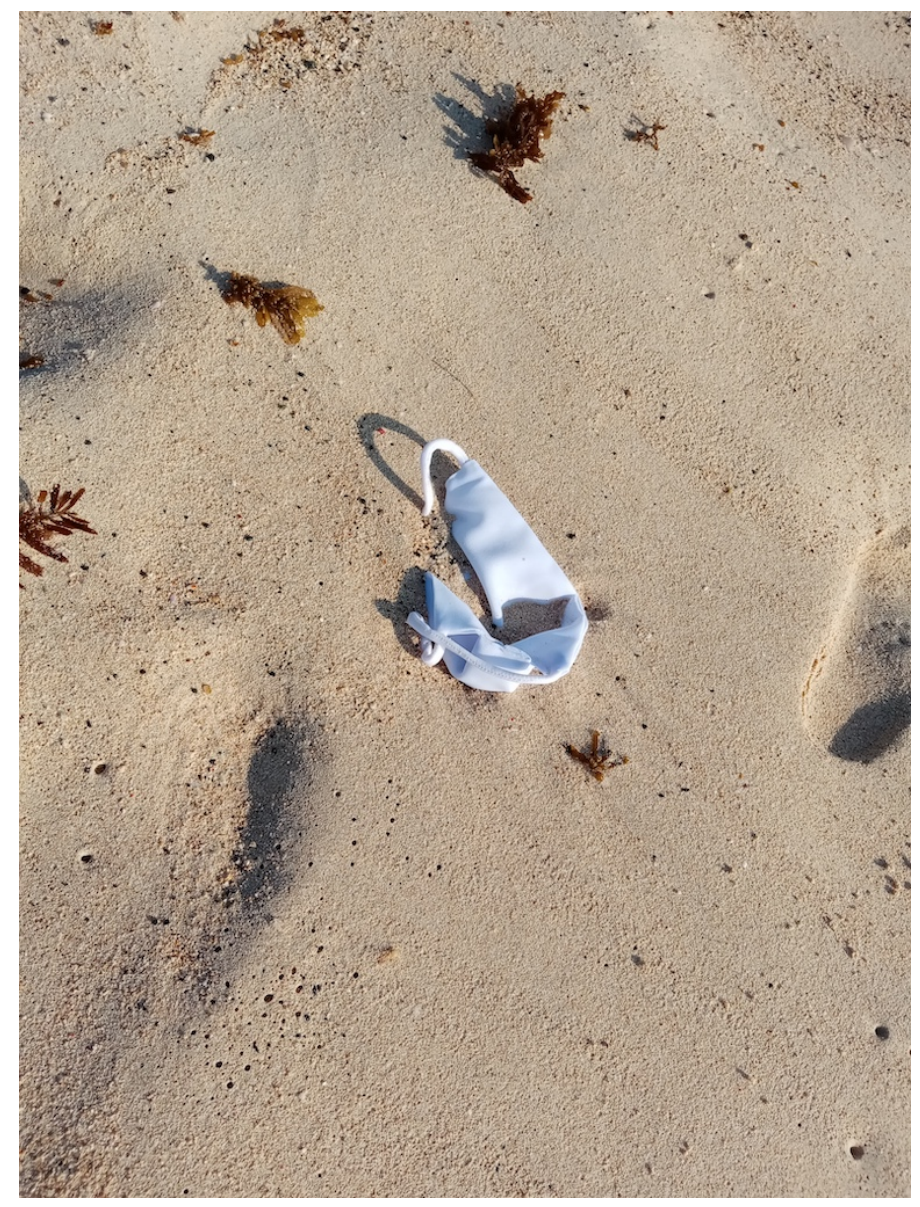

Fig 3. Reusable face mask discarded on a beach in Davao Oriental, Philippines. This was contributed by a volunteer; however, it was not included in the data set as it lacked GPS coordinates. (Photo by Antonette Rita Marie Blanco)

By presenting this paper, we aim to draw attention on the environmental problem that the COVID-19 pandemic brings and contribute information that can be useful in addressing this new threat as early as possible. We also draw attention to the potential of citizen science to address some of the challenges in marine litter research in the Philippines and elsewhere. Further studies are encouraged to gather more information on litter associated with COVID-19 and the impacts of such materials in the environment that can be used in legislation of government policies to address this future ecological problem. Advancement of citizen science research is also recommended.

\section{Declaration of competing interest}

The authors declare that they have no competing financial interests or personal relationship that could have appeared to influence the work reported in this paper. The result presented here are the initial findings of a larger project being conducted by the authors. 


\section{References}

Abreo, N.A.S., 2018. Marine plastics in the Philippines: a call for research. Philipp. Sci. Lett. 11, 18-19.

Abreo, N.A.S., Blatchley, D., Superio, M.D., 2019a. Stranded whale shark (Rhincodon typus) reveals vulnerability of fi Iter-feeding elasmobranchs to marine litter in the Philippines. Mar. Pollut. Bull. 141, 79-83. https://doi.org/10.1016/j.marpolbul.2019.02.030

Abreo, N.A.S., Kobayashi, V.B., 2021. First evidence of marine litter associated 1 with COVID-19 in Davao Gulf, Mindanao, Philippines. Philipp. J. Sci. 150, 1145-1149.

Abreo, N.A.S., Thompson, K.F., Arabejo, G.F.P., Superio, M.D.A., 2019b. Social media as a novel source of data on the impact of marine litter on megafauna: The Philippines as a case study. Mar. Pollut. Bull. 140, 51-59. https://doi.org/10.1016/j.marpolbul.2019.01.030

Alcala, A.C., Ingles, J.A., Bucol, A.A., 2008. Review of the biodiversity of Southern Philippine Seas. Philipp. Sci. 45, 1-61. https://doi.org/10.3860/psci.v45i0.991

Burgess, H.K., DeBey, L.B., Froehlich, H.E., Schmidt, N., Theobald, E.J., Ettinger, A.K., HilleRisLambers, J., Tewksbury, J., Parrish, J.K., 2017. The science of citizen science: Exploring barriers to use as a primary research tool. Biol. Conserv. 208, 113-120.

https://doi.org/10.1016/j.biocon.2016.05.014

Coram, A., Abreo, N.A.S., Ellis, R.P., Thompson, K.F., 2021. Contribution of social media to cetacean research in Southeast Asia: illuminating populations vulnerable to litter. Biodivers. Conserv. 30, 2341-2359. https://doi.org/10.1007/s10531-021-02196-6

De-la-Torre, G.E., Aragaw, T.A., 2021. What we need to know about PPE associated with the COVID-19 pandemic in the marine environment. Mar. Pollut. Bull. 163, 1-5.

de Sousa, D.F.B., 2020. Pros and Cons of Plastic during the COVID-19 Pandemic. Recycling 5, 1-17.

https://doi.org/doi:10.3390/recycling5040027

Fadare, O.O., Okoffo, E.D., 2020. Covid-19 face masks: A potential source of microplastic fibers in the environment. Sci. Total Environ. 737, 1-4.

Hiemstra, A., Rambonnet, L., Gravendeel, B., Schilthuizen, M., 2021. The effects of COVID-19 litter on animal life. Anim. Biol. 71, $215-231$. https://doi.org/10.1163/15707563-bja10052

Hyder, K., Townhill, B., Anderson, L.G., Delany, J., Pinnegar, J.K., 2015. Can citizen science contribute to the evidence-base that underpins marine policy? Mar. Policy 59, 112-120. https://doi.org/10.1016/j.marpol.2015.04.022

Jambeck, J.R., Geyer, R., Wilcox, C., Siegler, T.R., Perryman, M., Andrady, A., Narayan, R., Law, K.L., 2015. Plastic waste inputs from land into the ocean. Science (80-.). 347, 768-771. https://doi.org/10.1126/science.1260352

Lasut, M.T., Weber, M., Pangalila, F., Rumampuk, N.D.C., Rimper, J.R.T.S.L., Warouw, V., Kaunang, S.T., Lott, C., 2018. From Coral Triangle to Trash Triangle - How the Hot spot of Global Marine Biodiversity Is Threatened by Plastic Waste 107-113. https://doi.org/10.1007/978-3-319-712796

Lee, E., Chen, Y., Mcdonald, M., Neill, E.O., 2020. Dynamic Response Systems of Healthcare Mask Production to COVID-19: A Case Study of Korea. Systems 8, 1-17.

Neto, H.G., Bantel, C.G., Browning, J., Fina, N. Della, Ballabio, T.A., de Santana, F.T., Britto, M.D.K. e, Barbosa, C.B., 2021. Mortality of a juvenile Magellanic penguin (Spheniscus magellanicus, Spheniscidae) associated with the ingestion of a PFF-2 protective mask during the Covid-19 pandemic. Mar. Pollut. Bull. 166, 1-5. 